\title{
Cognition and cerebral blood flow in lateralised Parkinsonism: lack of functional lateral asymmetries
}

\author{
A Agniel, P Celsis, G Viallard, J L Montastruc, O Rascol, J F Demonet, \\ J P Marc-Vergnes, A Rascol
}

\begin{abstract}
Cognitive and cerebral blood flow (CBF) lateral asymmetries have been quantified in 23 right handed patients with lateralised idiopathic Parkinson's disease. Thirteen patients who had predominant right-sided symptoms (RPD) were compared with ten who had predominant left-sided symptoms (LPD). The patient subgroups were matched for age, education, duration of illness, disease severity and medication. Normalised asymmetries scores were calculated from the data obtained with a test battery and SPECT. No correlation was found between laterality of motor Parkinsonian symptoms and cognitive or haemodynamic asymmetry scores.
\end{abstract}

Service de Neurologie, CHU Purpan,

Toulouse

A Agniel

A Rascol

INSERM U230, CHU

Purpan, Toulouse

$P$ Celsis

$G$ Viallard

J F Demonet

J P Marc-Vergnes

Laboratoire de

Pharmacologie,

Médicale et Clinique,

INSERM U317 CHU

Purpan, Faculté de

Médecine, Toulouse,

France

J L Montastruc

O Rascol

Correspondence to:

Dr Agniel, Service de

Neurologie, CHU Purpan,

F-31059 Toulouse Cedex,

France

Received 14 September 1990 and in revised form

9 January 1991.

Accepted 11 January 1991
Most of the studies on cognitive functioning or cerebral blood flow in Parkinson's disease (PD) have been performed in patients with bilateral signs of the disease and few studies have concentrated on neuropsychological performances ${ }^{1-8}$ or haemodynamic characteristics ${ }^{9-13}$ in patients with lateralised PD.

Moreover, the relationship between the neuropsychological profile and the $C B F$ pattern has never been examined in patients with lateralised PD. The purpose of this study was to investigate the relationship between the neuropsychological profiles and the laterality of motor symptoms of patients with lateralised PD.

\section{Materials and methods \\ Patients}

Twenty three right handed patients $(11$ males, 12 females) with a presumed diagnosis of haemodynamic patterns according to the

Table 1 Historical and clinical data in groups, mean (1SD)

\begin{tabular}{lccc}
\hline & $\begin{array}{l}\text { Controls } \\
(n=20)\end{array}$ & $\begin{array}{l}L P D \\
(n=10)\end{array}$ & $\begin{array}{l}R P D \\
(n=13)\end{array}$ \\
\hline Sex $(\mathrm{M} / \mathrm{F})$ & $9 / 11$ & $5 / 5$ & $6 / 7$ \\
Age (years) & $60(5)$ & $55(8)$ & $60(5)$ \\
Duration of education (years) & $13(5)$ & $11(4)$ & $12(5)$ \\
Disease duration (months) & & $29(20)$ & $29(22)$ \\
UPDRS & $12(7)$ & $11(9)$ \\
Treatment: & & 6 \\
$\quad$ no treatment & 4 & 1 \\
anticholinergic & 2 & 3 \\
bromocriptine & & 2 & 3 \\
\hline
\end{tabular}

LPD = predominant left-sided symptoms.

$\mathrm{RPD}=$ predominant right-sided symptoms.

idiopathic PD and asymmetry in Parkinsonian motor symptoms were evaluated (table 1). All patients were rated as stage $1(n=13)$ or 2 $(n=10)$ on the Hoehn and Yahr scale. ${ }^{14}$ Parkinsonian motor symptoms were considered as asymmetrical if there was a side to side difference of at least two points in at least two of the three main symptoms of the Parkinsonian syndrome (that is, tremor, rigidity, akinesia) rated on the motor examination of the Unified Parkinson's Disease Rating Scale (UPDRS version 1, a close variant of UPDRS version 3, 1987). ${ }^{15}$ Thirteen patients had predominantly right sided Parkinsonism (RPD) and ten had predominant symptoms to the left side (LPD). Patients with RPD had a mean (1 SD) age of 60 (5), a 12 (5) years mean duration of education, an average disease duration of 29 (22) months and a mean motor examination UPDRS score of 11 (9). Patients with LPD had a mean age of 55 (8), an 11 (4) years mean duration of education, an average disease duration of 29 (20) months and a mean motor examination UPDRS score of 12 (7). None of the patients presented with any sign of mental deterioration, and none was taking levodopa. Ten patients did not take any antiParkinsonian drugs. Three had been treated with an anticholinergic medication (one RPD and two LPD), and five with bromocriptine (three RPD and two LPD). Treated patients were deprived of any anti-Parkinsonian drug 48 hours before the study. As previously reported, ${ }^{16}$ the discontinuation of medication for two days resulted in the reappearance of the Parkinsonian symptoms.

\section{Controls}

Twenty healthy right handed volunteers, nine males and 11 females, mean (1 SD) age 60 (5), were included as controls. Mean (SD) level of education was 13 (5) years. The volunteers had neurological and psychiatric examinations to exclude neurological disability or history of psychiatric illness. None was hypertensive and none had a history of migraine. All controls had normal CT scan.

Informed consent was obtained from controls and from patients.

\section{Cognitive testing}

Subjects were evaluated with a battery of cognitive tasks adapted from Bentin $e t a l^{6}$ for assessing lateral hemispheric cognitive asymmetries. The battery consisted of nine tests. Five tests were considered to achieve preferential testing of right hemisphere func- 
tions, and four preferential testing of left hemisphere functions. The five tests of right hemisphere functions were the letter recognition (T1), Benton facial recognition (T2), WAIS block design (T3), WAIS object assembly (T4) and light pattern (T5) tests. The four tests of left hemisphere functions were the letter search (T6), WAIS digit span (T7), Benton verbal fluency (T8) and light sequence (T9) tests. The light pattern and light sequence were adapted for automated administration on a McIntosh micro-computer and a French version of the letter recognition and letter search tests was designed.

The cognitive asymmetry score $\mathrm{C}$ was calculated according to

$\mathrm{C}=\mathrm{Z}_{\mathrm{R}}-\mathrm{Z}_{\mathrm{L}}$

where

$\mathrm{Z}_{\mathrm{R}}=\sum_{\mathrm{k}=1}^{\mathrm{k}=5}\left[\mathrm{~S}\left(\mathrm{~T}_{\mathrm{k}}-\mathrm{m} \mathrm{T}_{\mathrm{k}}\right) / \mathrm{S}_{\mathrm{Tk}}\right] / 5$ and

$Z_{L}=\sum_{k=6}^{k=9}\left[S\left(T_{k}-m T_{k}\right) / S_{T k}\right] / 4$

$\mathrm{m}_{\mathrm{Tk}}$ and $\mathrm{S}_{\mathrm{Tk}}$ being the mean and standard deviation of the performance obtained on test $T_{K}$ in the control group. Thus $C$ represents the distance, expressed in number of standard deviations (Z-score), of the subject's cognitive asymmetry from the mean cognitive asymmetry of the control group. By construction, mean $\mathrm{C}$ equals zero in controls. A negative $\mathrm{C}$ denotes a relative better performance of the left hemisphere, whereas positive $C$ reflects better performance of the right hemisphere.

\section{$C B F$ measurement}

Regional cerebral blood flow (CBF) was assessed using a single photon emission tomograph (Tomomatic 64, Medimatic, Copenhagen) and intravenous injection of Xenon ${ }^{133}$ (2200 MBeq). Data were collected from three transverse slices simultaneously, each being $2 \mathrm{~cm}$ thick, parallel and centred at 1, 5, and $9 \mathrm{~cm}$ above the canthomeatal plane respectively. The in-plane resolution was $1.7 \mathrm{~cm}$. During the $4 \mathrm{mn}$ data collection, patients were kept at rest, eyes closed, and $\mathrm{PCO} 2$ was continuously recorded using a transcutaneous electrode and a Kontron 634 pCO2 monitor. $\mathrm{CBF}$ was calculated using the Celsis et al algorithm. ${ }^{17}$ According to the method previously described, ${ }^{18}$ regions of interest (ROIs) were defined in the mid slice $(\mathrm{OM}+5)$ and regional CBF values were thus calculated in five cortical regions, (the superior frontal, middle and inferior frontal, insular, parietotemporal and occipital regions), and two subcortical regions (anterior and posterior) for each hemisphere. In addition to absolute flow values, region-to-slice ratios were calculated to assess the flow distribution in the mid slice.

The haemodynamic asymmetry score $\mathrm{H}$ was calculated for each subject according to

$\mathrm{H}=\left(\mathrm{D}_{\mathrm{F}}-\mathrm{mD}_{\mathrm{F}}\right) / \mathrm{SD}_{\mathrm{F}}$

where

$D_{F}=2\left(F_{r}-F_{1}\right) /\left(F_{r}+F_{1}\right)$
$F_{r}$ and $F_{1}$ being the mean flows in the right and left hemisphere respectively, $\mathrm{mD}_{\mathrm{F}}$ and $\mathrm{SD}_{\mathrm{F}}$ being the mean and standard deviation of $D_{F}$ obtained in the control group where mean $\mathrm{H}$ equals zero by construction. Negative $H$ denotes a higher flow in the left hemisphere whereas positive $\mathrm{H}$ reflects higher flow in the right one.

Results are expressed as mean (1 SD). Significance was assessed using unpaired (comparisons between controls and patients) and paired (comparisons between hemispheres) Student $t$ tests.

\section{Results}

Table 2 gives the mean score in LPD and RPD patients and in controls on the nine tests of the battery for cognitive asymmetry. Only one test of the cognitive battery, the WAIS object assembly, reflected a significant difference among the groups. Post-hoc comparisons indicated that LPD patients performed significantly worst compared with RPD patients and controls. Table 3 gives the mean CBF in the hemispheres and the mean value observed in the five cortical and two subcortical regions of each hemisphere (mid slice, $\mathrm{OM}+5 \mathrm{~cm}$ ). There was no significant difference between hemispheres for LPD and RPD patients, neither in the cortical nor in the subcortical areas. Compared with controls, CBF was decreased in the subcortical regions of patients, bilaterally, but the difference failed to reach significance. Accordingly, the patient's CBF did not differ significantly from that of controls in any ROI of the mid slice.

Mean (1 SD) values of the asymmetry scores (table 4$)$ in RPD [ $0.21(0.52),-0.80(0.9)]$ and LPD patients $[0.26(0.93),-0.16(0.7)$ for $C$ and $\mathrm{H}$ respectively, were not significantly different. Similarly the average of the absolute values of the asymmetry scores (the unsigned values, a measure of the magnitude of the asymmetry) did not differ significantly between PD groups or compared with controls, with respect to $C$ (RPD: 0.4, LPD: $0 \cdot 7$, controls: $0.55)$ and $H$ (RPD: 1, LPD: $0 \cdot 6$, controls: 0.8 ). Moreover, and as for controls, there was no correlation between the cognitive and the haemodynamic scores $(r=0 \cdot 109)$.

\section{Discussion}

The aim of this study was to assess the existence of lateral asymmetries in CBF in patients with lateralised Parkinson's disease and to correlate such asymmetries with the cognitive profiles which has been described in these patients.

We failed to find any relationship between laterality of Parkinsonian motor symptoms and both cognitive and haemodynamic lateral asymmetries. Indeed, there was no relationship between the side of predominant motor symptoms and the cognitive or haemodynamic scores. The only cognitive test whose score was significantly different according to the lateralisation of PD was the WAIS object assembly, the lower performances being observed in the LPD 
Table 2 Mean score (1 SD) on cognitive tests in patients and controls

\begin{tabular}{|c|c|c|c|}
\hline & Controls ( $n=20$ ) & $L P D(n=10)$ & $R P D(n=13)$ \\
\hline $\begin{array}{l}\text { Right hemisphere tests } \\
\text { T1 } \\
\text { T2 } \\
\text { T3 } \\
\text { T4 } \\
\text { T5 }\end{array}$ & $\begin{array}{c}3 \cdot 7(3 \cdot 9) \\
45 \cdot 4(3 \cdot 4) \\
8 \cdot 6(3 \cdot 06) \\
9 \cdot 2(2 \cdot 7) \\
14 \cdot 7(1 \cdot 7)\end{array}$ & $\begin{array}{r}4 \cdot 4(3 \cdot 3) \\
42 \cdot 6(3 \cdot 3) \\
7 \cdot 2(2 \cdot 9) \\
7 \cdot 2(2)^{\star} \\
14 \cdot 1(2 \cdot 5)\end{array}$ & $\begin{array}{r}4 \cdot 8(2 \cdot 3) \\
45 \cdot 1(2 \cdot 8) \\
8 \cdot 5(2 \cdot 4) \\
9 \cdot 1(1 \cdot 7) \\
14 \cdot 9(1 \cdot 2)\end{array}$ \\
\hline $\begin{array}{l}\text { Left hemisphere tests } \\
\text { T6 } \\
\text { T7 } \\
\text { T8 } \\
\text { T9 }\end{array}$ & $\begin{array}{c}6.34(3.3) \\
9.5(1.9) \\
33.05(11.6) \\
14.4(2.5)\end{array}$ & $\begin{array}{c}7 \cdot 4(3) \\
9 \cdot 7(2 \cdot 5) \\
21 \cdot 4(10) \\
15 \cdot 5(1 \cdot 8)\end{array}$ & $\begin{array}{r}6 \cdot 6(2 \cdot 1) \\
6 \cdot 6(2 \cdot 1) \\
27 \cdot 7(7 \cdot 5) \\
15 \cdot 4(1 \cdot 5)\end{array}$ \\
\hline
\end{tabular}

LPD = predominant left-sided symptoms

RPD = predominant right-sided symptoms.

${ }^{\star} \mathrm{p}<0.01$ vs Controls and RPD.

The five tests of right hemisphere functions were the letter recognition (T1), Benton facia recognition (T2), WAIS block design (T3), WAIS object assembly (T4) and light pattern (T5) tests. The four tests of left hemisphere functions were the letter search (T6), WAIS digit span (T7), Benton verbal fluency (T8) and light sequence (T9) tests.

Table 3 Mean CBF values (1SD) in patients and controls

\begin{tabular}{lllllll}
\hline & \multicolumn{2}{l}{ Controls $(n=20)$} & \multicolumn{2}{l}{$L P D(n=10)$} & \multicolumn{2}{l}{$R P D(n=13)$} \\
\hline & Left & Right & Left & Right & Left & Right \\
Mean hemispheric CBF & $53(11)$ & $53(10)$ & $51(6)$ & $51(6)$ & $51(11)$ & $50(10)$ \\
Mean cortical CBF` & $53(9)$ & $53(10)$ & $52(6)$ & $52(7)$ & $52(11)$ & $50(10)$ \\
Mean subcortical CBF & $59(13)$ & $55(11)$ & $50(6)$ & $49(6)$ & $51(12)$ & $50(11)$
\end{tabular}

LPD = predominant left-sided symptoms.

RPD = predominant right-sided symptoms

* Mean CBF in the five cortical regions (namely the superior frontal, middle and inferior frontal, insular, parietotemporal and occipital regions) of the mid slice $(5 \mathrm{~cm}$ above the canthomeatal plane) for each hemisphere.

+ Mean CBF in the 2 subcortical regions (anterior and posterior) of the mid slice $(5 \mathrm{~cm}$ above the canthomeatal plane) for each hemisphere.

Table 4 Mean (1SD) on cognitive and haemodynamic asymmetry scores in patients and controls

\begin{tabular}{lllr}
\hline & Controls $(n=20)$ & $L P D(n=10)$ & $R P D(n=13)$ \\
\hline Cognitive asymmetry score & $0(0.69)$ & $0.26(0.93)$ & $\begin{array}{r}0.21(0.52) \\
\text { Haemodynamic asymmetry score }\end{array}$ \\
\hline
\end{tabular}

LPD = predominant left-sided symptoms

$\mathrm{RPD}=$ predominant right-sided symptoms

group. This finding agrees with a preferential involvement of the right hemisphere in visuospatial tasks. Indeed, although we recognise that the performance on the object assembly test may be impaired due to various dysfunctions (right parietal dysfunction, left parietal dysfunction, frontal lobe lesions), we also know that, most of the time, such an impairment results from visuospatial deficits associated with right parietal dysfunction.

Our results are consistent with previous reports that found no differences between RPD and LPD patients on several neuropsychological tests: Hubert et al found that "while overall cognitive impairment increased with advancing disease, the pattern of neuropsychological impairments was not different with respect to laterality of motor symptoms". Oyebode $e t$ al $^{7}$ noted that side of symptoms had no influence on deficits in word fluency and visuospatial imagery, whereas these two deficits correlated with disease severity. Boller et $a l^{8}$ found no difference between RPD and LPD on measures of visuospatial skills and Bentin et al found no differences on a cognitive battery designed to maximise hemispheric differences. Conversely, our results do not agree with the findings of Blonder et $a l,{ }^{2}$ Spicer et al, ${ }^{3}$ Stark- stein et $a l,{ }^{4}$ Direnfeld et $a l .{ }^{5}$ These support the existence of some correlation between the neuropsychological performance and the lateralisation of predominant motor signs (RPD were more impaired on measures of memory, verbal fluency and language-related tasks than were patients with LPD, whereas left-sided. symptoms were associated with spatial deficits). These discrepancies could be due to differences in clinical characteristics of patients (duration of disease, disease severity) or in methodological differences. Indeed, the positive results reported in these last studies have been obtained in patients with longer duration of disease and higher severity of symptoms than our patients, or when compared with controls and not by direct comparison between LPD and RPD patients. The data on haemodynamic and metabolic studies in patients with lateralised PD give conflicting results and whether the blood flow or the binding of dopaminergic ligands are decreased, unchanged or increased in brain regions contralateral to the symptomatic limbs is unclear. ${ }^{9-12}$

To our knowledge, the correlation between quantitative differences in hemisphere cognitive performance and hemisphere perfusion or metabolism has never been reported. In this study, the scores on the cognitive and haemodynamic indexes of lateral asymmetries did not differ systematically between patients and controls, and consequently, there was no correlation between cognitive and blood flow asymmetries in patients. It is worth comparing this negative finding with the absence of correlation we found between changes in CBF and in neuropsychological scores after administration of levodopa in PD. ${ }^{19}$ Our method can be considered sensitive as it allowed Bentin et $a l^{6}$ to correctly classify the side of damage in $93 \%$ of patients with verified unilateral lesions and as it demonstrated the existence of correlated cognitive and haemodynamic lateral asymmetries in patients with dementia of $\mathrm{Alz}$ heimer type. ${ }^{20}$ It was, however, perhaps insufficient in showing lateral differences in the patients of this study, since 10 of them showed bilateral motor symptoms (stage 2 on the Hoehn and Yahr scale), even though motor dysfunction was indeed clearly asymmetrical in these patients. The absence of lateral functional asymmetries, except for motor symptoms, may be due to the fact that our patients were suffering from mild PD and did not present any sign of mental deterioration. Lees and $S$ ith $^{21}$ noted only subtle cognitive frontal type difficulties in mildly Parkinsonian patients without impairment of general intellectual function. It is possible that our patients presented such cognitive difficulties, but these might be too slight or not sufficient to induce significant abnormalities in our battery of lateral cognitive tasks. Whereas the cortical changes seen in Alzheimer's disease (that is, senile plaques and neurofibrillary tangles) have been described in Parkinsonian patients, they were observed particularly in aged and demented patients. ${ }^{22}$ As duration of disease was short and deterioration absent in our patients, it is 
likely that they were free of such a noticeable cortical involvement. Other causes, such as the dopaminergic loss from the caudate ${ }^{24}$ or Lewy body disease ${ }^{25}$ may be the source of the cognitive impairment as well. The emergence of observable lateral functional asymmetries with progression of the disease will be assessed through a follow up study of these patients, which is currently in progress in our laboratory.

We thank Chantal Blanchard and Thérèse Pujol for their technical assistance.

1 Huber SJ, Freidenberg DL, Shuttleworth EC, Paulson GW Clapp LE. Neuropsychological similarities in lateralised parkinsonism. Cortex 1989;25:461-70.

2 Blonder LX, Gur RE, Gur RC, Saykin AJ, Hurtig HI. Neuropsychological functioning in hemiparkinsonism. Neuropsychological functioning in

3 Spicer KB, Roberts RJ, LeWitt PA. Neuropsychological performance in lateralised parkinsonism. Arch Neurol 1988;45:429-32.

4 Starkstein S, Leiguarda $R$, Gershanik O, Berthier $M$ Neuropsychological disturbances in hemiparkinson's disease. Neurology 1987;37:1762-4.

5 Direnfeld LK, Albert ML, Volicer L, Langlais PJ, Marquis J, Kaplan E. Parkinson's disease. The possible relationship of laterality to dementia and neurochemical findings. Arch Neurol 1984;41:935-41.

6 Bentin S, Silverberg R, Gordon HW. Asymmetrical cog nitive deterioration in demented and parkinson patients. Cortex 1981;17:533-44.

7 Oyebode JR, Barker WA, Blessed G, Dick DJ, Britton PG. Cognitive functioning in Parkinson's disease: In relation to prevalence of dementia and psychiatric diagnosis. Brit Psychiatry 1986;149:720-5.

8 Boller F, Passafiume D, Keefe NC, Rogers K, Morrow L, Kim Y. Visuospatial impairment in parkinson's disease. Role of perceptual and motor factors. Arch Neurol 1984 41:485-90.

9 Leenders K, Wolfson L, Gibbs J, Wise R, Jones T, Legg N Regional cerebral blood flow and oxygen metabolism in Parkinson's disease and their response to L-Dopa. $J$ Cere Blood Flow Metabol 1983;3:suppl:S488-9.

10 Rutgers AWF, Lakke JPWF, Paans AMJ, Vaalburg W, Korf $\mathrm{J}$. Tracing of dopamine receptors in hemiparkinsonism with positron emission tomography (PET). J Neurol Sci 1987;80:237-48.
11 Garnett ES, Nahmias C, Firnau G. Central dopaminergic pathways in hemiparkinsonism examined by positron emission tomography. Can J Neurol Sci 1984;11:174-9.

12 Henriksen L, Boas J. Regional cerebral blood flow in hemiparkinsonian patients. Emission computerised tomography of inhaled 133 Xenon before and after levodopa. Acta Neurol Scand 1985;71:257-66.

13 Perlmutter JS, Raichle ME. Regional cerebral blood flow in hemiparkinsonism. Neurology 1985;35:1127-34.

14 Hoehn MM, Yahr MD. Parkinsonism: onset, progression, and mortality. Neurology 1967;17:427-42.

15 Fahn S, Elton R, and the members of the UPDRS Development Committee. Unified Parkinson's disease rating scale. In: S Fahn, D Marsden, D Calne, et al. eds. Recent developments in Parkinson's disease, vol 2. Florham Park New Jersey: McMillan Health Information, 1987:153-63.

16 Rascol O, Montastruc JL, Senard JM, Demonet JF, Simonetta M, Rascol A. Two weeks of treatment with deprenyl (selegiline) does not prolong L-dopa effect in parkinsonian patients: A double-blind cross-over placebo-controlled trial. Neurology 1988;38:1387-91.

17 Celsis P, Goldman T, Henriksen L, Lassen NA. A method for calculating regional cerebral blood flow from emission computed tomography of inert gas concentrations. J Computed tomography of inert gas

18 Celsis P, Agniel A, Puel M, Rascol A, Marc-Vergnes JP. Focal cerebral hypoperfusion and selective cognitive deficit in dementia of the Alzheimer type. $J$ Neurol Neurosurg Psychiatry 1987;50:1602-12.

19 Montastruc JL, Celsis P, Agniel A, et al. Levodopa-induced regional cerebral blood flow changes in normal volunteers and patients with Parkinson's disease. Lack of correlation with clinical or neuropsychological improvements. Movement Disorders 1987;4:279-89.

20 Celsis P, Agniel A, Puel M, et al. Lateral asymmetries in primary degenerative dementia of the Alzheimer type. A correlative study of cognitive, haemodynamic and EEG data, in relation with severity, age at onset and sex. Cortex 1990;26:585-96.

21 Lees AJ, Smith E. Cognitive deficits in the early stages of Parkinson's disease. Brain 1983;106:257-70.

22 Boller F, Mizutani T, Roessman U, Gambetti P. Parkinson disease, dementia and Alzheimer disease: clinicopathological correlation. Ann Neurol 1980;7:329-35.

23 Dubois B, Hauw JJ, Ruberg M, Serdaru M, Javoy-Agid F, Agid Y. Démence et maladie de Parkinson: corrélations biochimiques et anatomo-cliniques. Rev Neurol 1985; 141:184-93.

24 Brown RG, Marsden CD. Cognitive function in Parkinson's disease: from description to theory. TINS 1990;13:21-9.

25 Hansen L, Salmon D, Galasko D, et al. The Lewy body variant of Alzheimer's disease: A clinical and pathologic entity. Neurology 1990;40:1-8.

\section{Neurological stamp}

\section{Leonardo da Vinci 1452-1519}

Leonardo, famous as an artist, was also a scientist, architect, engineer and geologist. He shares with Avicenna and Fracastoro (two doctors in this series) the distinction of recognising the true origin of fossils. He designed flying machines, a turbine engine, a steamboat, and drew plans for a military tank and a submarine. Although not a physician, he was a master anatomist who predated Vesalius.

His chalk drawings remained buried for over 200 years until discovered by William Hunter in 1784 . Da Vinci had shown the human body in more than 750 anatomical illustrations. This included sketches of muscles, bones, the cerebrum, blood vessels and viscera. He dissected more than 30 bodies, discovered the frontal and maxillary sinuses and described in detail the structure and function of heart valves. He was the first to show anatomy in cross section and applied this to the brain, and was also the first to make a crude diagram of the cranial nerves, optic chiasm and brachial and lumbar plexuses. His contribution to neurological anatomy included wax casts of the four ventricles. This was the first known attempt at anatomical injection. Da Vinci also showed the mechanism of action of antagonistic groups of muscles.

He found that sectioning a digital nerve produced anaesthesia so that "the finger no longer has sensation even when placed in a fire". He recognised the function of the spinal cord as a conductor and that a frog could die

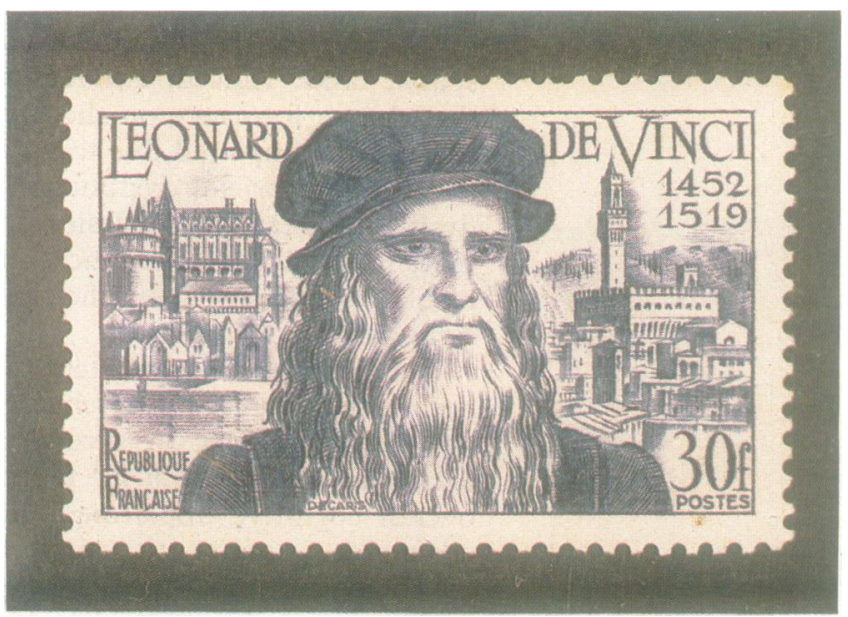

suddenly following perforation of its medulla oblongata. He located the soul at the top of the spinal cord. In a drawing of his wax casts of the ventricular system, he followed the old medieval scheme allocating sensation, cognition and memory to the lateral, third and fourth ventricles, respectively.

France honoured him with a stamp issued in 1952 on the 500 th anniversary of his birth (Stanley Gibbons No 1150, Scott No 682). 